\title{
Research on the Optimization of Boiler Efficiency based on Artificial Bee Colony Algorithm
}

\author{
Jun-Ta Wu ${ }^{1,3}$, Yuan-Biao Zhang ${ }^{2,3}$, Gui-Sen Xu', Yi Lin ${ }^{4} \&$ Xin-Guang $\mathrm{Lv}^{2,3}$ \\ ${ }^{1}$ Electrical and Information School, Jinan University, Zhuhai 519070, China \\ ${ }_{2}^{2}$ Packaging Engineering Institute, Jinan University, Zhuhai 519070, China \\ ${ }^{3}$ Key Laboratory of Product Packaging and Logistics of Guangdong Higher Education Institutes, Jinan \\ University, Zhuhai 519070, China \\ ${ }^{4}$ International Business School, Jinan University, Zhuhai 519070, China \\ Correspondence: Jun-Ta Wu, Key Laboratory of Product Packaging and Logistics of Guangdong Higher \\ Education Institutes, Jinan University, Zhuhai 519070, China. E-mail: 418655377@qq.com
}

Received: July 20, $2014 \quad$ Accepted: July 28, $2014 \quad$ Online Published: August 30, 2014

doi:10.5539/cis.v7n4p30 URL: http://dx.doi.org/10.5539/cis.v7n4p30

\begin{abstract}
This paper is to seek effective scheme of boiler efficiency optimization, it uses Artificial Bee Colony (ABC) algorithm to optimize boiler efficiency based on the model of boiler combustion efficiency. First, an optimization model of boiler efficiency, which takes boiler efficiency function as optimization objective, is set up according to the heat loss of boiler combustion. Moreover, the operating parameters affecting boiler efficiency is determined. Then $\mathrm{ABC}$ algorithm is used to solve the optimal value of boiler efficiency. The result of the research shows that the optimization of boiler efficiency based on $\mathrm{ABC}$ algorithm can quickly obtain optimal parameters for running boiler, so that the optimal boiler efficiency can be got.
\end{abstract}

Keywords: boiler efficiency, optimization, artificial bee colony algorithm, genetic algorithm

\section{Introduction}

Boiler is a typically complex system which is multi-input, multi-output, nonlinear as well as non-self-balanced, and boiler combustion of power station is complex physical and chemical process. Therefore how to improve the combustion efficiency of boiler has always been an important issue in this field (Shi, 2010).

At present, researches on the optimization of boiler efficiency have been in-depth. Zhang et al. (1999) proposed a new computational model of boiler efficiency on the basis of the research on operating parameters of boiler combustion; Hao et al. (2004) used a method based on artificial network (ANN) and genetic algorithm (GA) for modeling the carbon burnout behavior in a pulverized coal fired boiler and optimizing boiler efficiency; Kusiak and Song (2006) introduced a data-mining approach to optimize combustion efficiency of a coal-fired boiler; Zhao and Wang (2009) combined support vector regression (SVR) with simplified model of boiler efficiency to improve boiler efficiency and to reduce the NOx emission. Gu et al. (2010) set up the boiler combustion model of power station with least squares support vector machine (LS-SVM) and used GA for optimization. Zhang et al. (2012) introduced the partial least squares vector machine (SVM) to set up boiler efficiency model of coal-fired power plant.

For the present, the optimization of boiler efficiency based on GA is common. However, GA is unstable during the process of optimization. On the basis of the established model of boiler efficiency, this paper introduces ABC algorithm for the research on the optimization of boiler efficiency, which conquers the unsteadiness of GA.

$\mathrm{ABC}$ algorithm is a meta-heuristic algorithm on the basis of group theory, which was proposed by Karaboga and Basturk in 2005 and improved by Karaboga et al (Shen, 2012). Now this algorithm has received much attention. Karaboga et al. used ABC algorithm for optimizing multivariable functions (2007) and compared the performance of $\mathrm{ABC}$ algorithm with that of Differential Evolution(DE), Particle Swarm Optimization (PSO) and Evolutionary Algorithm (EA) for multi-dimensional numeric problems (2009). Xu and Duan (2010) used ABC in visual target recognition for aircraft at low altitude. Omkar et al. (2011) introduced ABC for multi-objective design optimization of composite structures. Akay and Karaboga (2012) introduced modified versions of ABC 
algorithm for efficiently solving real-parameter optimization problems.

This paper introduces $\mathrm{ABC}$ algorithm into the field of the optimization of boiler efficiency and verify its effectiveness. First, we research heat loss of running boiler and set up the optimization model of boiler efficiency based on anti-balance method. In this way, the operating parameters which affect boiler efficiency are determined. Then boiler efficiency is optimized based on $\mathrm{ABC}$ algorithm with boiler efficiency function as optimization objective. Finally, we research on the performance of ABC algorithm according to the optimization result and compare $\mathrm{ABC}$ algorithm with $\mathrm{GA}$.

\section{The Optimization of Boiler Efficiency}

\subsection{Establishment of the Optimization Model of Boiler Efficiency}

\subsubsection{Background Information of Boiler}

Boiler is one of the key equipment for thermal power station, whose efficiency has direct impact on the economy of the station. In modern power station, boiler efficiency is the key performance indicator to reflect the operating conditions of boiler. Additionally, power station uses anti-balanced method to compute boiler efficiency, that is:

$$
\eta_{g l}=q_{1}=100-\sum_{i=2}^{6} q_{i} \quad \%
$$

due to unburned gas $q_{3}$, heat loss due to unburned carbon $q_{4}$, heat loss due to radiation $q_{5}$, heat loss due to sensible heat in $\operatorname{slag} q_{6}$. Where, $q_{i}(i=1,2, \cdots, 6)$ respectively represent net heat $q_{1}$, heat loss due to exhaust gas $q_{2}$, heat loss

\subsubsection{Heat Loss of Boiler}

1) Heat loss due to exhaust gas

In the thermal balance test, in order to simplify the calculation, the following empirical equation for calculating heat loss due to exhaust gas is used $(\mathrm{Wu}, 2006)$ :

$$
q_{2}=\left(m+n \alpha_{p y}\right)\left(1-\frac{q_{4}}{100}\right) \frac{\theta_{p y}-t_{a m b}}{100} \quad \%
$$

Where $m=0.5, n=3.45, \alpha_{p y}$ is excess air coefficient, $\theta_{p y}$ is exhaust gas temperature, $t_{a m b}$ is ambient temperature.

2) Heat loss due to unburned gas

Heat loss due to unburned gas comes from inflammable gas in exhaust smoke, such as $\mathrm{CO}_{2}, \mathrm{CH}_{4}$, heavy hydrocarbons and so on, which do not emit their combustion heat. In order to simplify the calculation, we assume $C O$ is the only product of incomplete combustion gas. Therefore, the following empirical equation is used to calculate heat loss due to unburned gas based on content of $C O$ (Sun, 2008):

$$
q_{3}=\lambda \alpha_{p y} V_{C O} \quad \%
$$

Where, factor $\lambda=3.2, V_{C O}$ is volume percentage of $C O$ in exhaust smoke.

From relevant literature (Gao, 2009), we know that:

$$
V_{C O}=\frac{21-(1+\beta) V_{R O_{2}}-V_{O_{2}}}{0.605+\beta} \quad \%
$$

Where $\beta=0.102, V_{R O_{2}}=13.05(\%), V_{\mathrm{RO}_{2}}$ is volume percentage of $\mathrm{SO}_{2}$ and $\mathrm{CO}_{2}$ in exhaust smoke, $\mathrm{VO}_{2}$ is volume percentage of $\mathrm{O}_{2}$. Then we can get the relational expression between $V_{\mathrm{CO}}$ and $V_{\mathrm{O}_{2}}$ :

$$
V_{C O}=\frac{\mu-V_{O_{2}}}{\omega} \quad \%
$$

In the above equation, $\mu=6.6189, \omega=0.707$. Substituting Equation (5) into Equation (3), then we can get Equation (6) after rearranging:

$$
q_{3}=\lambda \alpha_{p y} \frac{\mu-V_{O_{2}}}{\omega} \quad \%
$$

3) Heat loss due to unburned carbon 
Heat loss due to unburned carbon consists of three parts including heat loss due to coal slag, heat loss due to leakage of coal and heat loss due to fly ash. In this paper, the research object is the pulverized coal furnace, which does not have leakage of coal. For the running boiler, we analyze weight percentage of combustible material in coal slag and fly ash, $C_{h z}(\%)$ and $C_{f h}(\%)$. Therefore, heat loss due to unburned carbon can be calculated by Equation (7) (Wu, 2006):

$$
q_{4}=\frac{B A_{a r}}{Q_{r}}\left(\frac{a_{h z} C_{h z}}{100-C_{h z}}+\frac{a_{f h} C_{f h}}{100-C_{f h}}\right) \quad \%
$$

Where $B$ is the calorific value of combustible material, $A_{a r}$ is ash content of as received basis in fuel, $Q_{r}$ is gross calorific value of as received basis.

$a_{h z}, a_{f h}$ respectively represent the percentage of coal slag content and fly ash content in total amount of fuel ash. In addition, we get the following equation from gray balance $(\mathrm{Wu}, 2006)$ :

$$
a_{h z}+a_{f h}=1
$$

In this paper, $a_{h z}=0.1$, so we can know $a_{f h}=0.9$.

4) Heat loss due to radiation

Heat loss due to radiation has little change when the load of boiler changes. As a matter of fact, the relative value of Heat loss due to radiation is inversely proportional to boiler load (Sun, 2008). The commonly used calculation equation is:

$$
q_{5}=-\frac{h X}{100 X_{0}}+d \quad \%
$$

Where $h=0.33, d=0.495, X_{0}$ is rated load of boiler unit, $X$ is current load of boiler unit.

5) Heat loss due to sensible heat in slag

There is heat loss due to sensible heat in slag because the temperature of coal slag and transudatory coal exhausted by boiler is usually above $600 \sim 800^{\circ} \mathrm{C}$. In this paper, the research object is the pulverized coal furnace, which does not have transudatory coal. So Heat loss due to sensible heat in slag can be calculated by Equation (10) (Wu, 2006):

$$
q_{6}=a_{h z} \frac{100}{100-C_{h z}}(c \vartheta)_{h z} \frac{A_{a r}}{Q_{r}}
$$

Where, $(c \vartheta)_{h z}$ is enthalpy of coal slag.

\subsubsection{Model of the Optimization of Boiler Efficiency}

Power station uses Equation (1) to compute boiler efficiency based on anti-balanced method. Substituting Equation (2), Equation (6), Equation (7), Equation (9) and Equation (10) into Equation (1), we can get boiler efficiency function:

$$
\begin{aligned}
\eta_{g l}= & 100-\left[\left(m+n \alpha_{p y}\right)\left(1-\frac{q_{4}}{100}\right) \frac{\theta_{p y}-t_{a m b}}{100}+\lambda \alpha_{p y} \frac{\mu-V_{O_{2}}}{\omega}\right. \\
& +\frac{B A_{a r}}{Q_{r}}\left(\frac{a_{h z} C_{h z}}{100-C_{h z}}+\frac{a_{f h} C_{f h}}{100-C_{f h}}\right)+\left(-\frac{h X}{100 X_{0}}+d\right) \\
& \left.+a_{h z} \frac{100}{100-C_{h z}}(c \vartheta)_{h z} \frac{A_{a r}}{Q_{r}}\right] \%
\end{aligned}
$$

We fit the relationship between enthalpy of coal slag $(c \vartheta)_{h z}$ and exhausted gas temperature $\theta_{p y}$ based on the data from relevant literature (Wu, 2006), so that we get Equation (12):

$$
(c \vartheta)_{h z}=0.0002887 \theta_{p y}^{2}+0.6851 \theta_{p y}+26.76
$$

Taking the boiler whose rated load is $300 \mathrm{MW}$ for an example, we can get the value of some parameters: 
$\alpha_{p y}=1.205, t_{a m b}=20\left({ }^{\circ} \mathrm{C}\right), X_{0}=300(\mathrm{MW}), A_{a r}=14.70(\%), \quad B=32866(\mathrm{KJ} / \mathrm{kg}), \quad C_{h z}=2(\%) ，$ $Q_{r}=25020(\mathrm{KJ} / \mathrm{kg})$. Then we can know that boiler efficiency $\eta_{g l}$ changes as $(c \vartheta)_{h z}, C_{f h}, V_{O_{2}}$ and $X$ change. Making these four parameters as independent variables, boiler efficiency function can be expressed as Equation (13):

$$
\eta_{g l}=f\left(\theta_{p y}, C_{f h}, V_{O_{2}}, X\right)
$$

After determining the range of variables when boiler is running, the optimization model of boiler efficiency is set up:

$$
\begin{array}{ll}
\text { Max } & \eta_{g l}=f\left(\theta_{p y}, C_{f h}, V_{O_{2}}, X\right) \\
\text { s.t. } & 120 \leq \theta_{p y} \leq 140 \\
& 5 \leq C_{f h} \leq 7 \\
& 4 \leq V_{O_{2}} \leq 6 \\
& 200 \leq X \leq 300
\end{array}
$$

\subsection{The Optimization of Boiler Efficiency based on ABC Algorithm}

Based on the optimization model of boiler efficiency, we use $\mathrm{ABC}$ algorithm and set appropriate parameters of $\mathrm{ABC}$ algorithm to optimize boiler efficiency. When it comes to the optimization of boiler efficiency, GA is unstable during the process of the optimization and easy to fall into local optimal solution. However, ABC algorithm has quick global convergence speed and stable optimization process. In addition, the optimization result of $\mathrm{ABC}$ algorithm is better than that of GA.

\subsubsection{Brief Introduction of ABC Algorithm}

$\mathrm{ABC}$ algorithm is proposed according to the intelligent foraging behavior of bees and is used to optimize multidimensional function and multimodal function. Compared with the traditional searching algorithm, $\mathrm{ABC}$ algorithm has the advantages of quick convergence, less parameters, easy implementing and simple calculation. In addition, it is much less likely to fall into local optimization (Shen, 2012).

In the algorithm, artificial bees consist of three types of bees: employed bees, onlooker bees and scout bees. Among the bees, the amount of employed bees is equal to the amount of onlooker bees, being half of the colony amount. Additionally one employed bee only corresponds to one food source, that is to say, the amount of employed bees is equal to the amount of food sources. When an employed bee gives up the food, it translates into a scout bee. As we know, different types of bees have different duty. Employed bees collect nectar having been found and convey the information about food to onlooker bees which are near honeycomb. While onlooker bees wait in dance area and select food sources according to the information about food. And scout bees search for new food sources in the space nearby spontaneously and randomly.

At the beginning of searching for food sources, scout bees search environment to find food. After having found food, scout bees translate into employed bees and collect nectar. At the same time, employed bees carry nectar back to honeycomb, after which they can return to the place where they find food sources or convey food information to onlooker bees by dancing in dance area. If food source has been thoroughly mined, corresponding employed bees translate into scout bees and continue to search for new food sources in the space nearby randomly. As for Onlooker bees, they waiting in honeycomb select food sources with high fitness according to dance. The higher the frequency of dance is, the better the food source is. In ABC algorithm, food source location represents feasible solutions of optimization question, and nectar amount of food source represents quality (fitness) of corresponding solution.

\subsubsection{Algorithm Design and Implementation}

In the optimization model of boiler efficiency based on $\mathrm{ABC}$ algorithm, one food source represents a feasible solution of decision variables including $(c \vartheta)_{h z}, C_{f h}, V_{O_{2}}$ and $X$, and information of food sources represent the value of variables. Nectar amount of food sources represents the corresponding value of objective function, which is boiler efficiency in this paper. Additionally, search scope of bee colony represents the range of decision variations: $120 \leq \theta_{p y} \leq 140,5 \leq C_{f h} \leq 7,4 \leq V_{O_{2}} \leq 6,200 \leq X \leq 300$.

The parameters of $\mathrm{ABC}$ algorithm is setting as the following: dimensionality $\operatorname{dim}=4$, population amount ColonySize $=10$, food source amount $s n=5$, the controlling parameter of the abandon of food sources limit $=20$, 
maximum cycling frequency MaxCycles $=200$.

Therefore, the implementation steps of ABC algorithm are shown as the following (Jia, 2013):

Step1 Algorithm is initialized, and scout bees generate initial solutions $x_{i j}$ by Equation(15):

$$
x_{i j}=x_{j}^{\min }+\operatorname{rand}(0,1)\left(x_{j}^{\max }-x_{j}^{\min }\right)
$$

Where $i=1,2, \cdots, s n, j=1,2, \cdots, \operatorname{dim}, s n$ is the amount of food sources(the initial solutions), dim is the dimension of the solution. After the initial solutions are generated, their fitness are calculated.

When the cycling starts again, the continuous frequency of non-improvement of $x_{i}$, trial ${ }_{i}$, is initialized to 0 . During the searching, the cycling won't stop until it has reached the maximum cycling frequency MaxCycles, or has been beyond the allowable error.

Step2 Employed bees search for new food by Equation (16):

$$
v_{i j}=x_{i j}+\phi_{i j}\left(x_{i j}-x_{k j}\right)
$$

Where $j$ is an integer generated randomly within[1,dim], $k$ is another integer not equal to $i$ which generates within $[1, s n], \phi_{i j}$ is a random number within $[-1,1]$.

When search finishes, new solution will be compared with the previous one and the solution with higher fitness is selected out based on Greedy Algorithm.

Step3 Onlooker bees select food sources according to probability calculated by Equation (17):

$$
p_{i}=\frac{\text { fitness }_{i}}{\sum_{i=1}^{s n} \text { fitness }_{i}}
$$

Where fitness $s_{i}$ is the fitness of a food source and $\sum_{i=1}^{s n}$ fitness $_{i}$ is the sum of fitness of all food sources.

Step4 Determine whether there is a food source to give up. If trial ${ }_{i}$ is greater than a given controlling parameter limit, the food source has run out. Therefore, the employed bee gives up the corresponding solution and translates into a scout bee to search for new solution.

Step5 Determine whether algorithm should end. First the number of iterations is increased, Cycle $=$ Cycle +1 . Then if Cycle > MaxCycles, algorithm ends and output the best solution. Otherwise, return to Step 2 to continue the loop.

\subsubsection{Result Analysis of ABC Algorithm}

Taking boiler efficiency function as optimization objective, we use ABC algorithm to optimize the boiler efficiency and get the optimal boiler efficiency which is $96.19 \%$. The optimal decision variables are shown Table 1:

Table 1. The optimal solution of ABC algorithm

\begin{tabular}{ccccc}
\hline Decision variable & $\theta_{p y}$ & $O_{2}$ & $C_{f h}$ & $X$ \\
\hline Optimal value & 120 & 7 & 4 & 300 \\
\hline
\end{tabular}


Iteration results during the optimization process of $\mathrm{ABC}$ algorithm are shown in Figure 1:

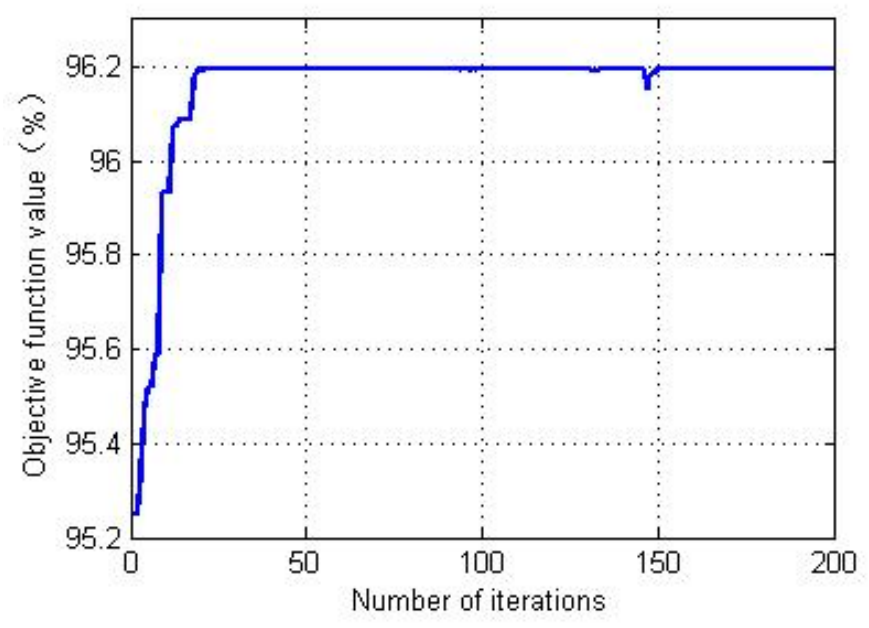

Figure 1. The optimization process of $\mathrm{ABC}$ algorithm

From Figure 1, we can draw a conclusion that ABC algorithm has quick global convergence speed. After about 20 times of iterations, the global optimal value is got and the following iteration results remain near the global optimal value. In brief, the whole optimization process is considerably stable.

In order to verify the validity of $\mathrm{ABC}$ algorithm, we make the algorithm run 20 times independently and average their results. Meanwhile 3 indicators are defined to describe the performance of ABC algorithm: mean, the average of the optimal value of 20 times of running; std, the standard deviation of the optimal values of 20 times of running; max, the global optimal value of all running. Where mean represents the gathered degree of the optimization, std represents the stability during the optimization process, and max represents the ability to avoid local optimal value.

The optimization process of the global optimal value of 20 times of running is shown in Figure 2:

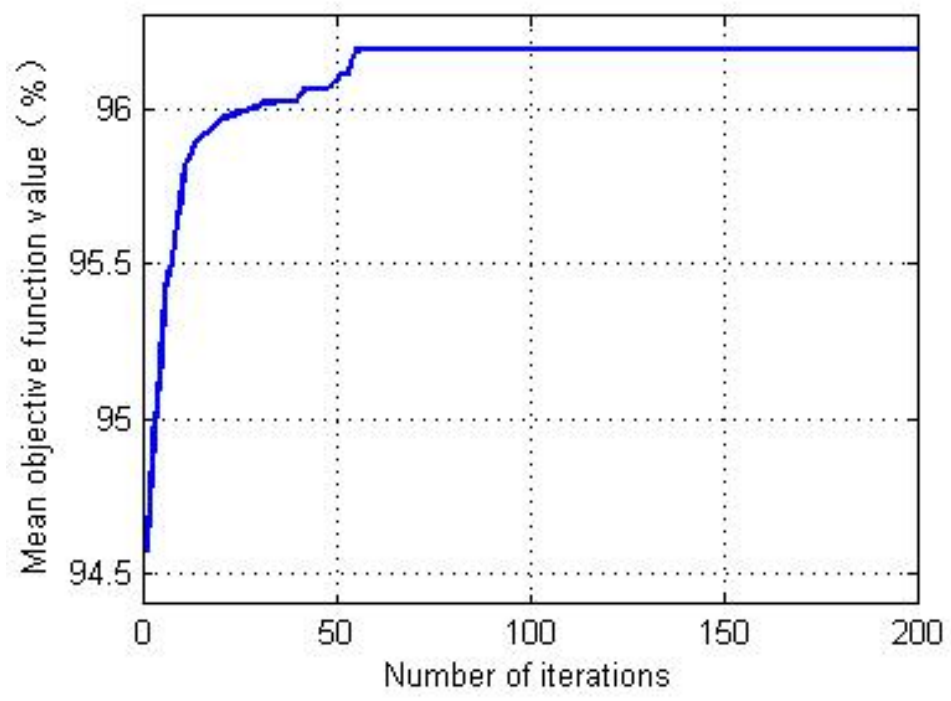

Figure 2. The optimization process of 20 times of running

From Figure 2, we can know ABC algorithm gets the global optimal solution after about 60 times of iterations, which indicates the average convergence speed of 20 tiems of running is quick. In the latter period of the algorithm, the average of optimal value after each of iteration is steadily near the global optimal value, further 
indicating the stability of $\mathrm{ABC}$ algorithm in the optimization of boiler efficiency.

Indicators to describe the algorithm based on the results of 20 times of running are shown by Table 2 :

Table 2. The Indicators of the performance of $\mathrm{ABC}$ algorithm

\begin{tabular}{cccc}
\hline Index & mean & std & $\max$ \\
\hline Value & $96.19 \%$ & $2.92 \mathrm{e}-14$ & $96.19 \%$ \\
\hline
\end{tabular}

From Table 2, we know that mean, the average of the optimal values of 20 times of running, is the same as $\max$, the global optimal value. Additionally the optimization results gathered near the global optimal value, which indicates the high gathered degree of the optimization based on $\mathrm{ABC}$ algorithm. And the standard deviation of the optimal values of 20 times of running is very close to zero, indicating the stable optimization process as well as the small difference among the optimization results. Therefore the performance of ABC algorithm is excellent.

\subsubsection{Comparison between ABC Algorithm and GA}

We use GA to optimize the boiler efficiency, setting population mutation probability as 0.05 , setting crossover probability as 0.9 , and making the number of iterations 200 . After the running of the algorithm, we get the optimal boiler efficiency which is $95.93 \%$. Then we compare ABC algorithm with GA.

Table 3. The comparison of optimal solution between ABC algorithm and GA

\begin{tabular}{cccccc}
\hline & $\theta_{p y}$ & $O_{2}$ & $C_{f h}$ & $X$ & $\eta_{g l}$ \\
\hline $\mathrm{ABC}$ & 120 & 7 & 4 & 300 & $96.19 \%$ \\
\hline $\mathrm{GA}$ & 122.87 & 6.99 & 4.61 & 236.61 & $95.93 \%$ \\
\hline
\end{tabular}

As Table 3 shows, the optimization result of ABC algorithm is better than that of GA. Moreover, we compare the optimization process of the two kinds of algorithm, which is shown in Figure 3:
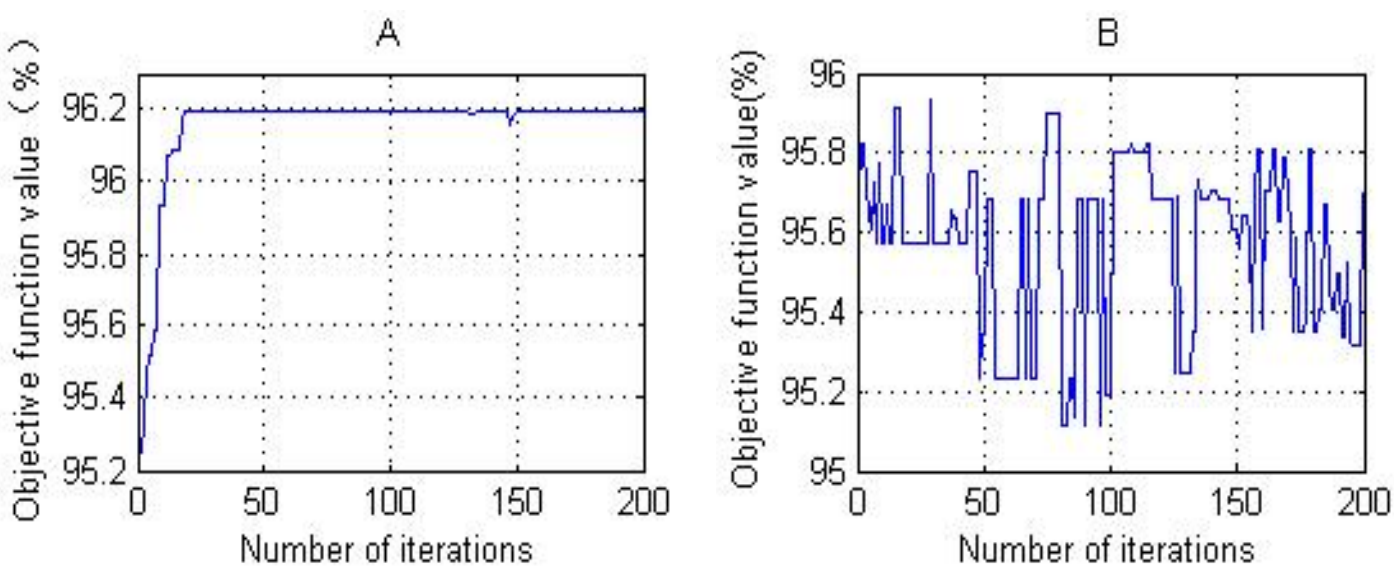

Figure 3. The comparison of the optimization process between $\mathrm{ABC}$ algorithm and GA

Where, Figure $\mathrm{A}$ is the optimization process of $\mathrm{ABC}$ algorithm while Figure $\mathrm{B}$ is the optimization process of GA. As Figure A shows, we get the global optimal value after 20 times of iterations, and the latter optimization results maintain near the global optimal value; From Figure B, we know the local optimal value is got after about 30 times of iterations. However, the latter optimization solution is poor and the optimization process of GA is unstable. Comparing the two figures, we can draw a conclusion that $\mathrm{ABC}$ algorithm is faster and more efficient. Meanwhile Figure 3 indicates that $\mathrm{ABC}$ algorithm has quick global convergence speed and stable optimization process. Therefore in the field of the optimization of the boiler efficiency, ABC algorithm is better than GA. 


\section{Conclusion}

Boiler is a complex system, whose combustion efficiency is of great significance for sustainable development of energy and economy. However, this paper has shown $\mathrm{ABC}$ algorithm, implementing optimization based on dynamic interaction between bees and environment, is an ideal method for boiler efficiency optimization.

In this paper, we first set up the optimization model of boiler efficiency on basis of research on heat loss of running boiler, then we used quick-convergence $\mathrm{ABC}$ algorithm to optimize the boiler efficiency. The research proved that this method can obtain satisfactory results. In addition, introducing $\mathrm{ABC}$ algorithm to optimize the boiler efficiency can make the optimization of the boiler efficiency more efficient and faster. It also has practical significance to use $\mathrm{ABC}$ algorithm creatively in the field of the optimization of boiler efficiency. Finally, we compared the optimization result of $\mathrm{ABC}$ algorithm with that of GA. The comparison reflected the superior performance of $\mathrm{ABC}$ algorithm and highlighted the superiority of $\mathrm{ABC}$ algorithm in the field of the optimization of boiler efficiency.

$\mathrm{ABC}$ algorithm is a type of swarm intelligence optimization algorithm, having promising prospects. The research and development of $\mathrm{ABC}$ algorithm will gradually deepen because of its practicability and superiority in the field of the optimization of boiler efficiency, so that more actual problems can be solved.

\section{Acknowledgements}

The authors acknowledge the financial support of this research by the Key Laboratory of Product Packaging and Logistics of Guangdong Higher Education Institutes, the Fundamental Research Funds for the Central Universities, the project of the Natural Science Foundation of Guangdong Province (No.S2012010008773), and the projects of Zhuhai Science, Technology, Industry, Trade and Information Technology Bureau (No.2011B050102013 \& 2012D0501990033).

\section{References}

Akay, B., \& Karaboga, D. (2012). A modified artificial bee colony algorithm for real-parameter optimization. Information Sciences, 192, 120-142. http://dx.doi.org/10.1016/j.ins.2010.07.015

Gao, L. X., Yuan, L. J., Zhou, Z. N., \& Li, C. (2009). New way to ascertain optimal excess air coefficient. Coal Mine Machinery, 8, 16.

Gu, Y. P., Zhao, W. J., \& Wu, Z. S. (2010, June). Combustion optimization for utility boiler based on least square-support vector machine. In Zhongguo Dianji Gongcheng Xuebao(Proceedings of the Chinese Society of Electrical Engineering) (Vol. 30, No. 17, pp. 91-97). Chinese Society for Electrical Engineering.

Hao, Z., Qian, X., Cen, K., \& Jianren, F. (2004). Optimizing pulverized coal combustion performance based on ANN and GA. Fuel Processing Technology, 85(2), 113-124. http://dx.doi.org/10.10 16/S0378-3820(03)00155-3

Jia, R. M.. (2013). The improvements and applications of Artificial Bee Colony algorithm (Unpublished master's thesis). Guang Xi University for Nationalities, Guang Xi, China.

Karaboga, D., \& Akay, B. (2009). A comparative study of artificial bee colony algorithm. Applied Mathematics and Computation, 214(1), 108-132. http://dx.doi.org/10.1016/j.amc.2009.03.090

Karaboga, D., \& Basturk, B. (2007). A powerful and efficient algorithm for numerical function optimization: artificial bee colony (ABC) algorithm. Journal of global optimization, 39(3), 459-471. http://dx.doi.org/10.1007/s10898-007-9149-x

Karaboga, D., \& Basturk, B. (2008). On the performance of artificial bee colony (ABC) algorithm. Applied soft computing, 8(1), 687-697. http://dx.doi.org/10.1016/j.asoc.2007.05.007

Karaboga, N. (2009). A new design method based on artificial bee colony algorithm for digital IIR filters. Journal of the Franklin Institute, 346(4), 328-348. http://dx.doi.org/10.1016/j.jfranklin.2 008.11.003

Kusiak, A., \& Song, Z. (2006). Combustion efficiency optimization and virtual testing: A data-mining approach. Industrial Informatics, IEEE Transactions on, 2(3), 176-184. http://dx.doi.org/10.110 9/TII.2006.873598

Omkar, S. N., Senthilnath, J., Khandelwal, R., Narayana Naik, G., \& Gopalakrishnan, S. (2011). Artificial Bee Colony (ABC) for multi-objective design optimization of composite structures. Applied Soft Computing, 11(1), 489-499. http://dx.doi.org/10.1016/j.asoc.2009.12.008 
Qian, K., \& Su, G. S. (2011). Application of artificial bee colony algorithm to optimization of channel section. Advances in Science and Technology of Water Resources, 31(3), 57-60. http://dx.doi.org/1 0.3880/j.issn. 006-7647.2011.03.017

Shen, Z. J., Zhang, Y. B., Qi, H., Wu, Q. L., Xia, Y. H., \& Liu, J. L. (2012). Research on the Production Scheduling of Printing Enterprises Based on Artificial Bee Colony Algorithm. Advances in information Sciences and Service Sciences (AISS), 4(12), 256-265. http://dx.doi.o rg/10.4156/AISS.vol4.issue12.30

Shi, Y., Lu, J. G., \& Xuan, Z. X.. (2010). Boiler combustion modeling and optimization based on neural network and genetic algorithm. Computer Applications and Software, 6, 74.

Song, Z., \& Kusiak, A. (2007). Constraint-based control of boiler efficiency: A data-mining approach. Industrial Informatics, IEEE Transactions on, 3(1), 73-83. http://dx.doi.org/10.1109/TI I.200 6.890530

Sun, Q. L., Shen, J., \& Li, Y. G. (2004). Genetic algorithm-based integrated optimization of a combustion process for a coal-fired utility boiler. Journal of Engineering for Thermal Energy and Power, 19(1), 85-88.

Sun, Q. L. (2008). The Research of Data Mining in Boiler operation optimization (Unpublished master's thesis). North China Electric Power University, Beijing, China.

Wang, H., Tang, Z. J., \& Fan, R. (2010). Application of wasp colony algorithm in job-scheduling of equipment repair [J]. Computer Engineering, 7, 242-245.

Wu, W.l., et al. (2006). Boilers and equipments of boiler house. Beijing: Chinese Building Industry Publishing House.

Xu, C. F., \& Duan, H. B. (2010). Artificial bee colony (ABC) optimized edge potential function (EPF) approach to target recognition for low-altitude aircraft. Pattern Recognition Letters, 31(13), 1759-1772. http://dx.doi.org/10.1016/j.patrec.2009.11.018

Zhang, C. Q., Zheng, J. G., \& Wang, X. (2011). Overview of research on bee colony algorithms. Application Research of Computers, 9, 2. http://dx.doi.org/10.3969/j.issn.1001-3695.2011.0 9.001

Zhang, X. T., \& Wang P. H. (1999). New computing model for boiler efficiency. Power System Engineering, 4, 002.

Zhang, Y. F., Wang, J. C., \& Shi, Y. H. (2012). Coal-fired boiler efficiency modeling based on partial least squares support vector machines. Control and Instruments in Chemical Industry, 11, 12.

Zhao, H., \& Wang, P. H. (2009, March). Modeling and optimization of efficiency and NOx emission at a coal-fired utility boiler. In Power and Energy Engineering Conference, 2009. APPEEC 2009. Asia-Pacific (pp. 1-4). IEEE. http://dx.doi.org/10.1109/APPEEC.2009.4918493

\section{Copyrights}

Copyright for this article is retained by the author(s), with first publication rights granted to the journal.

This is an open-access article distributed under the terms and conditions of the Creative Commons Attribution license (http://creativecommons.org/licenses/by/3.0/). 